\title{
Bem-estar e comportamento animal: manifestações técnicas de diferentes matizes e qualidade na atuação profissional
}

\author{
Carla Forte Maiolino Molento \\ Coordenadora Laboratório de Bem-estar Animal, Universidade Federal do Paraná
}

Prezados leitores,

As áreas de bem-estar e comportamento animal podem ser consideradas relativamente novas no cenário científico, em meio à tradição de estudos em anatomia, nutrição e fisiologia, por exemplo. Entretanto, é possível perceber que nas últimas décadas o bem-estar animal e a etologia vêm se consolidando, tanto em termos de pesquisa quanto de ensino e extensão. Infelizmente, algo preocupante também vem ocorrendo. Em função do aumento da demanda relacionada a bem-estar animal e da instabilidade característica de uma área que apenas recentemente passou a ser lecionada durante a graduação, começa a surgir uma variância de qualidade na atuação dos profissionais.

O Brasil vem produzindo avanços de conhecimento sobre diagnóstico e intervenções em bem-estar animal baseados em ciência robusta, expressa por periódicos científicos de renome. Para atestar tal constatação, basta uma busca de publicações científicas de pesquisadores nacionais: vários resultados inspiradores estão disponíveis em canais de excelência. Por outro lado, notas técnicas contendo verdadeiras impossibilidades conceituais, que se pautam por questões alheias ao conhecimento na área de comportamento e bem-estar animal, também vem sendo publicadas, inclusive envolvendo serviços oficiais de nosso país.

É em tal contexto que este número especial da Revista Acadêmica: Ciência Animal sobre Bemestar e Comportamento Animal se apresenta, constituindo relevante colaboração para interação científica e respaldo do bom exercício profissional para todos aqueles que têm em suas atribuições responsabilidades para com os animais. No rol de artigos a seguir, a reflexão sobre importantes questões de bem-estar animal é estimulada.

Ofereço como aperitivo um comentário sobre o papel da Organização Mundial para a Saúde Animal (OIE) para o desenvolvimento do bemestar animal. A seriedade com que o tema é tratado pela Organização pode ser exemplificada pelo lançamento, em 2017, da Estratégia Global de Bemestar Animal da OIE. As estratégias de bem-estar animal constituem propostas de alto potencial de 
melhoria da qualidade de vida dos animais, sendo atualmente construídas em vários cenários. Como exemplos adicionais à Estratégia de Bem-estar Animal da OIE, temos a Estratégia de Bem-estar Animal da World Association of Zoos and Aquariums (WAZA) para animais silvestres em cativeiro e, para os animais envolvidos com a indústria de alimentos, há propostas recentes de adaptação da Análise de Perigos e Pontos Críticos de Controle, mais conhecida como HACCP, para subsidiar uma estratégia de bem-estar animal específica ao setor.

Assim, os avanços são concretos e objetivos, viabilizando atuação técnica de qualidade que se caracteriza, entre outros fatores, por um acompanhamento atento à literatura científica da área. $\mathrm{O}$ conhecimento em bem-estar $\mathrm{e}$ comportamento animal segue avançando e está logicamente vinculado ao bom exercício profissional e, em última instância, ao desenvolvimento de nosso país. Portanto, é com grande prazer que escrevo o editorial deste número valioso da Revista Acadêmica: Ciência Animal, da Pontifícia Universidade Católica do Paraná.

Boa leitura! Que a boa ciência seja nosso principal instrumento de trabalho! 